\title{
5 The Social Movement Scene of Labour
}

\begin{abstract}
This chapter analyses the social movement scene of labour and the catalytic role of the crisis in the rise of self-managed cooperatives and workers' collectives. Taking into consideration the vast increase in unemployment, the chapter explores the incorporation of self-managed structures in libertarian social centres, and shows how the social movement scene of labour moved beyond the margins of the usual audience of activists. By paying attention to the variety of decision-making systems, the formation of cooperatives' networks, the role of resources, as well as the different origins and evolution of self-management in Greece, this chapter discusses the development of the boundary enlargement process in the social movement scene of labour.
\end{abstract}

Keywords: Self-management; Social cooperatives; Workers' collectives; Labour movement

The term "social movement scene of labour" may be perhaps met with skepticism by those familiar with social movement studies. About 50 years ago the labour movement was not a distinct aspect of social movements; instead, it pervaded various forms of collective action. Nevertheless, the end of the 1960 signaled the advent of new social movements, bringing other actors to the forefront and enriching the activities, repertoires, frames and goals of the people taking to the streets. "Working class heroes" started to be replaced by middle-class citizens, while labour issues became marginal in the movements' agenda, compared to broader post-material claims against neoliberal globalization.

The case of Greece did not show any particular differences as we discussed in Chapter 2. Nevertheless, the advent of the economic crisis accelerated the process of boundary enlargement, giving way for the development of the social movement scene of labour with quite distinctive characteristics. The cultivation of the principles of self-organization on labour issues

Malamidis, Haris, Social Movements and Solidarity Structures in Crisis-Ridden Greece. Amsterdam, Amsterdam University Press 2021 DOI: $10.5117 / 9789463722438 / \mathrm{CHO} 5$ 
within political collectives acted as a catalyst for the transition towards the establishment of autonomous self-managed cooperatives and, to a lesser extent, the incorporation of self-managed structures within social centres. However, in terms of its reach, the social movement scene of labour moved beyond the margins of its usual audience, with the formation of self-managed cooperatives by several people belonging either at the periphery or outside of the social movement community. In this respect, the vast increase in unemployment and the normalization of precarious conditions in the labour market, combined with the formulation of a friendly legislative framework, were additional reasons for the rise of social cooperatives. By looking at the organizational structure, resources and identity, this chapter aims to explore the formation of the boundary enlargement process in the social movement scene of labour.

\subsection{Organizational Structure}

The idea of self-management as an alternative to both state and marketcontrolled management is central to the social movement scene of labour. In this respect, the internal organizational structure consists of one of the two important pillars (the other being resources) that distinguish self-managed endeavours from other types of corporations. Based on the data generated through our field research, we concentrate on the variety of assemblies and different forms of participation, the procedures of accession and withdrawal and the capacity of networking, in order to explore how the mechanism of emulation triggered coordinated action, contributing to the process of boundary enlargement.

\subsubsection{Assemblies and Participation}

In our quest to understand the organizational structure of cooperatives, the first points to observe are the decision-making procedures and their internal formation. In both cases, the mechanism of emulation is of utmost importance. The mechanism of emulation refers to 'the deliberate repetition within a given setting of a performance observed in another setting' (Tilly and Tarrow, 2007, p. 215). In our case, emulation reflects the way that social movement culture initially intervened to the scene of labour by transferring practices from one setting to the other. Contrary to other cases, in which the boundary enlargement process is triggered by changes, with regards to the social movement scene of labour, this process took place because 
emulation allowed activists to transfer social movement traditions and habits into the labour market.

Inspired by the social movement culture, self-managed cooperatives emphasize their differences with the corrupted cooperative movement of the past and pay great attention to participatory procedures. For this, the general assembly of members acquires a pivotal role in each cooperative and becomes the ultimate decision-making instrument for each of the cases studied. Against the tradition of the cooperative movement with the different shareholders, boards of directors and management councils, all the assemblies function under horizontal and direct-democratic procedures, where every member has one vote. Nevertheless, there is still a certain degree of variation which deserves our attention. Therefore, this section studies the different decision-making models that cooperatives apply, their internal organization in terms of tasks and responsibilities, as well as the different degrees of importance that members ascribe to the assemblies.

Akin to many political assemblies of the libertarian scene, members of Oreo Depo ${ }^{1}$ café-tavern-grocery store, have veto rights, while decisions in the cooperative are considered legitimate if they reach unanimity. If this does not work, the members try to find a compromising solution and discuss the issue in the next assembly (Int.30). Unanimity is also desirable for the bookstore of Akivernites Polities ${ }^{2}$, but the members have decided to operate by enhanced majority since, 'in case someone continues insisting on an issue without reaching unanimity, it might prove rather problematic' (Int.31). The same pretty much goes for Ekdosis ton Sinadelfon ${ }^{3}$ publishing house (Int.23), Youkali café (Int.48), the Eklektik café-grocery store (Int.26) and others as well, where the members try to work primarily on a consensual-synthetic approach, and in case there is great disagreement, they use enhanced majority.

Interestingly, the digital cooperative of Sociality distinguishes the decision-making model with regards to the subject discussed. In particular, when it comes to a business project, the members follow the procedure mentioned earlier; but once the project concerns a political collective, as for example the website development of a social movement organization (SMO), they follow a majoritarian model, where the issue is discussed in two consecutive assemblies and the right to veto exists (Int.28). These

1 Oreo Depo stands for Beautiful Depo and Depo is the name of the district in the eastern part of Thessaloniki.

2 Akivernites Polities stands for Drifted Cities as well as Ungoverned States.

3 Ekdosis ton Sinadelfon stands for Colleagues' Publications. 
differences prove some degree of internal variation but all point towards more democratic and participatory procedures. This brings us to the next aspect, which deals with the content of the assemblies and the cooperatives' internal operation.

Sociality cooperative distinguishes between projects which entail some political elements and others which are purely business. Unless a project is proposed by an individual or an organization with fascist characteristics, the cooperative accepts pretty much every offer that comes from the private sector. Each project is distributed among Sociality's members, who choose not to include any task-management issues in their assemblies. Instead, during their assemblies, which are open to the public, they focus on discussing political projects and the cooperative's long-term strategic planning (Int.28). Similar procedures have been implemented in the occupied factory of Vio.Me, where workers use daily meetings to coordinate the cooperative's everyday operation, and the monthly general assembly for long-term planning. However, not every cooperative uses similar mechanisms.

'Not even the chairs can change position if we don't decide it in the assembly' (Int.30), argued a member from Oreo Depo in her effort to emphasize that everything is discussed in the members' weekly assemblies. Compared to what is often argued about the new social movements and their loose structure, cooperatives seem to employ a rather well-defined organizational structure. The reasoning behind this lies in the members' efforts to protect the team from overenthusiasm, which may lead to unintended results. In order to clarify tasks, individual duties are distributed to the members during the assemblies. However, problems can arise as specific issues discussed tend to be quite time-consuming. For this reason, the members of Oreo Depo try to first communicate some issues via email, as in the case of vacation leave, before opening them to deliberation. The same logic also goes for the cooperative café-bookstore Poeta, with some members being responsible for the operation of the café and others for the bookstore, as a way of sharing responsibilities and tasks (Int.44). However, in some cases, the division of responsibilities takes on a slightly more organized character through the establishment of working groups.

Although some procedures, such as the distribution of the weekly shifts, have not been yet automated and are still discussed in the assemblies, the working groups established in Youkali café-tavern help to considerably ease the cooperative's operation (Int.48). These groups usually consist of two to four members and deal with various practical concerns; the kitchen group is responsible for suggesting the menu to the assembly, the events group deals with the political and social actions within the cooperative, 
the economics group pays closer attention to the financial arrangements of the cooperative, and so forth. Similar models followed in other collectives, with Pagkaki ${ }^{4}$ café-tavern cooperative applying an interesting distinction.

In particular, Pagkaki distinguishes between the practical tasks that concern the cooperative's operation and the political ones. Practical tasks can be considered as the collective's bureaucratic obligations, such as the payment of the bills; the creation of menus or financial monitoring; while political ones are the operation of the bookstore, attendance in the assemblies and committees that Pagkaki participates in, or even the creation of the music list and the response to emails (Int.49; Int.50). Depending on the issues at stake, tasks can be assigned either individually or collectively to the cooperative's members, whilst, like other cooperatives, members try to rotate in terms of shifts, tasks and participation in different working groups. Some of these tasks used to be paid, since members devoted a considerable amount of time (and thus labour). However, this practice was abandoned since the cooperative could not find an objective way to calculate how much time was required for each task.

A number of cooperatives use the internet in a crucial manner for their operation. Apart from the mailing list, Pagkaki cooperative has its own online forum, where every aspect of its operation is uploaded for internal consultation. This includes everything, from food recipes and technical instructions about the machinery, to the time span and recordings of each assembly. As the interviewees admit, the forum diminishes the potential for knowledge inequality, by giving information access to all the members and thus, prevents the rise of expertise and informal hierarchies. Although the case of social clinics recognizes that the virtual space of mailing lists grands members an impression of participation, the use of the internet in cooperatives is conceived only as an additional element to the physical operation of the assembly. This is also supported by Sociality, which, despite its expertise in digital tools of communication, urges its members to work at office in order to enhance communication and understanding. Commenting on that, an interviewee claimed that international experience shows that cooperatives tend to malfunction not because of market pressures but due to the members' internal fights. Therefore, face-to-face meetings are substantial for the cooperative economy' (Int.28). This opens up an interesting debate regarding the actual operation of the assemblies.

The cooperatives' small size and the members' friendly relations are two characteristics that quite often seemed to reduce the typical formality 
that assemblies have. In the case of Lacandona café-grocery store for instance, assemblies take place while the café operates and seem to be quite informal. As one of Lacandona's four members stated, 'since we are few, we meet each other daily; we coincide between the end of the day and the beginning of the night shift and this makes things easier' (Int.45). The café remains open also during the assemblies of Oreo Depo, with the latter usually lasting long, since they are interrupted due to the workload (Int.30). However, this is not always the case. More precisely, the assembly in Youkali has specific duration, takes place when the café is closed, and it is usually adjusted in a way that fits the programme of the members in charge of the most shifts (Int.48). Additionally, previous experience from Sporos and large assemblies of 30 people urged the members of Pagkaki to strongly emphasize the need to select one coordinator and another person responsible for keeping track of time during the assemblies. As the members argue, this method not only safeguards the smooth operation of the assembly, but also gives the attendants the impression that this is not a friendly chat, but rather a serious procedure taking place among colleagues (Int.49).

The different examples mentioned so far illustrate the central role of collective decision-making in self-managed cooperatives (Kokkinidis, 2015). At the same time, this variety depicts different approaches that urged collectives to adopt different organizational structures. Being the first to be established, Pagkaki is pictured as the role model for many cooperatives. Freeman (1972) could not agree more with one of the cooperative's members stating that 'we are supporters of structures, procedures and organization. Strictness and looseness, exceptions and flexibility are all very malleable' (Int.49). However, other interviewees pointed out that despite the usefulness of role-models, self-management on its own provides the workers with a great degree of flexibility. 'You are the one to construct the cooperative from the very beginning, it's your terms you apply, and you can make it as you wish' (Int.47). However, the missing link here is not the opposing views of the different cooperatives, but whether the collectives' actual composition of members remained the same through all these years. As the interviewee of Pagkaki explained,

depending on the group's constitution and what will be decided as its common ground in the meantime, the procedure might soften. [...] Some people prefer more organized processes, others do not. Thus, the internal dynamics are strong and continuous and each time a member enters, they enforce you to seek a new balance. (Int.49) 
This brings us to the next section, which concerns entry and exit procedures.

\subsubsection{Procedures of Entry and Exit}

Literature on social movements emphasizes that SMOs suffer from a relatively short lifespan (Diani, 2013). However, the costs of dissolution are much higher for the self-managed cooperatives, when compared to self-organized political and social groups, since the potential "death" of a cooperative automatically puts in danger the members' economic livelihood. In our context, most of the cooperatives struggle to define clear procedures with regards to their operation, and in most cases, they are quite functional. However, they do not seem to pay much attention to a potential re-shuffle of their members. Field research shows that most of the cooperatives deal with entry and exit procedures mostly when these take the form of an emergency, and particularly, when people should either enter the cooperative or leave. In these regards, entry and exit procedures of new and old members are rather important as they outline the manner in which self-managed practices are formed. At the same time, the internal dynamics surrounding entry and exit procedures direct us towards the mechanisms that enable the process of boundary enlargement to take place within the social movement scene of labour.

Self-managed cooperatives constitute complex hubs that gather characteristics from self-organized SMOs, blended together with responsibilities often met in typical enterprises. Interestingly, entry and exit procedures prove that operations in self-managed cooperatives are closer to the internal procedures of movement organizations than to enterprises. In these regards, the above-mentioned mechanism of emulation is also at play here.

Early social movement scholars argued that widespread discontent is the number one reason that prompts people to mobilize. In spite of that, the free-rider problem introduced by Olson, urged researchers to focus on selective incentives as a means of understanding why people are mobilized and join SMOs. In the language of rational-choice theorists, selective incentives have been translated into material ones (Staggenborg, 2011, pp. 31-34). In our attempt to examine the social movement scene of labour, many members of cooperatives emphasized that the sense of equality, as opposed to the competitive and precarious character of the neoliberal market environment, was the triggering point that turned them to self-management. 'Having a job that we like and from which we could live with dignity, as much as someone can live with dignity in this world' depicts a Poeta member's incentives, which 'together with the broader situation of emergency, meaning that there 
are no jobs, that you cannot even work as a (low paid) employee' (Int.44), prompted the members to set up the cooperative in the first place.

Nevertheless, material incentives are not the only factors that motivate people towards collective action. Many scholars bring forward more political incentives, such as the diffusion of political identity, solidarity incentives that are born due to friendly and social relations, as well as purposive incentives, like the sense of fulfillment when achieving a goal (Staggenborg, 2011, pp. 31-34). These seem to correspond to the incentives of the Allos Tropos social cooperative in Thessaloniki, of which the members' need for decent employment was coupled with more political questions, 'on the way that someone makes a living' (Int.24). As one member argued, 'returns cannot be always measured in money. The cooperative supports everyone; everyone gives what they can give and take what they need. We trust in personal relationships and everyone who enters the team should follow this logic' (Int.24). In a similar vein, when trying to find new members, Youkali cooperative pays stronger attention to the persons' political experience in collective action and social movements, rather than to their prior work experience. A member that was not in the initial team stated that,

the burden was mostly on political issues and experience in assemblies both in my case and in others that followed. The last two persons who entered (the cooperative), have never done this job; but together with the passion to learn it, we should also understand what shared responsibility and self-management means. The last criteria we set concerned racist and sexist behaviour. (Int.48)

To some degree, the aforementioned cases resemble the model followed by self-managed structures operating within social centres and squats. In these cases as well, prior work experience is not a requirement, with most of the criteria focusing on the active participation in the centres' assemblies and political activities (Int.51).

Whether they met in traditional SMOs or in the market environment, self-managed structures are rather closed groups. More precisely, they occupy a specific number of members, who are usually recruited on the basis of existing social and political networks, as a means of ensuring that a certain degree of trust and common understanding is already there. This informal rule is also confirmed by negative cases like Sociality, where there was no prior relationship with newcomers. In particular, when seeking new staff for the cooperative, Sociality issued a public advertisement. To the members' dislike, many people showed up to fill the position, but without 
any interest in learning how the cooperative functions. After this failure, the members decided to issue job openings only when they have ensured that potential candidates would already be aware of how the cooperative works and what goals it has (Int.28).

We mentioned earlier that cooperatives are hubs, which accommodate political elements in the way of working and living. These are also reflected in what social movement studies have underlined about the incentives to mobilization. For this reason, when too much attention is given to the political side, it may transform the cooperative into a political group and create problems for the economic side. On the contrary, by focusing only on its wellbeing, a cooperative may lose its political appeal and turn into a normal enterprise. Dealing with this dilemma, Pagkaki's potential members should balance their need for employment and their political desire to participate in the cooperative. As a matter of fact, there were times that the cooperative rejected people whose will to participate was based only on one of the two reasons (Int.49).

Similar to the entry procedures, the cooperatives' approaches to exit procedures reveal the burden of personal relations and political ethics. Internal disagreements stand as the number one reason that leads members to abandon the cooperatives, with the minority being usually the one to voluntarily withdraw their membership. Similar to Youkali, Ekdosis do not have specific entry and exit procedures. According to the members, once a potential newcomer agrees to the cooperative's principles, they automatically become a member with equal rights and obligations to the rest of the staff. The same also applies to the exit procedures, when, as it happened twice, members withdrew the same way they entered in the first place, since they could not comply with the cooperative's regulations. As an interviewee claimed, 'I am going to be the one to leave if I cannot work in this context; I am not going to ask you to leave' (Int.23).

So far, we have shown that the cooperatives' composition is based mostly on three characteristics: social networks and affinity groups (Int.25), such as friendly and family ties; political beliefs; and the need for employment. Although each of these characteristics may be considered more important than the other two for each cooperative, at one degree or another, these features are present in all the cases. At the same time though, these are the characteristics often found within traditional SMOs. Taking into consideration the entry and exit procedures, we can see that the cooperatives' pre-figurative approach, also common for SMOs, has triggered the mechanism of emulation, through which the members' initial incentives are also translated into the criteria for potential entries and exits. 
Before we proceed further, it is important to remind the reader that, as a mechanism, emulation should not be conceived as a stable practice that acts alone. On the contrary, as every other mechanism, it is subject to a dynamic approach that expects the mechanism to be evolved and developed, and most importantly to have interplay with other mechanisms. In this case, the mechanism of emulation is intertwined with the mechanism of category formation, which is analysed extensively in the identity factor. The mechanism of emulation helped the new cooperatives to imitate some of the SMOs' practices, but also to understand when these practices could reach a dead end. Field research reveals that the absence of relative experience in self-management, together with the mechanism of emulation might bring about problems in terms of entry and exit procedures.

Starting from the former one, similar to the technical help and support provided sometimes to SMOs by friends, familiars and sympathizers who are not members, respective practices have been observed in some cooperatives. More precisely, increased demand in the workforce encouraged cooperatives to add personnel for a short period of time, receiving equal payment but without becoming members or participating actively in the assemblies. An interviewee from Allos Tropos noted that some of their friends have occasionally worked paid shifts in the cooperative without being members (Int.24), while another one from Poeta admitted the same, due to difficulties in the early stage of the cooperative's development (Int.44). In both cases, interviewees claimed that newcomers enjoyed equal rights with the rest of the members and received the same compensation, despite the temporary character of their employment and their non-participation in the assemblies.

Similar examples can be found in other cooperatives. Health reasons forced a member of Lacandona to stay away for ten months and her position to be covered temporarily by a friend. Although equally paid, that person neither became a member of the cooperative, nor did she participate in the assemblies. According to the interviewees, despite the fact that the temporary newcomer did not become a member of the cooperative, no communication problem or issue of internal hierarchy emerged, since there was a mutual feeling of equality (Int.45). Youkali's experience is slightly different. The cooperative, in need of a temporary workforce, added two people to fill some shifts in the summer period. As a member recalled,

we made one bad decision. We told these people that since they are working just for some months, there is no need to also attend the assemblies. That was a mistake. Many issues rose due to this arrangement. Our approach in general is not to have employees. In this case, although they 
were not actual employees, practically they were. If something happened, I would be the responsible one, I would be at risk. So, there was hierarchy. Although work was of equal value, responsibility was not. (Int.48)

Some members were opposed to that decision, while others evaluated it positively, since a couple of months later one of these persons became a full member of the cooperative.

Similar occasions in other cooperatives have sparked discussions, debates and dilemmas regarding issues of morality and equality. These cases are simply a few examples that help us to shed light on some of the difficulties that might arise within self-managed cooperatives, due to undetermined procedures and a lack of prior experience. However, the exit procedures suffer from the negative effects of emulation as well. More precisely, cooperatives strive to implement a different logic from the capitalistic enterprises. This effort has sparked internal debates, with some members arguing against the right to dismiss the personnel since this is not in accordance with the cooperatives' social principles (Int.23), and others supporting that layoffs may be a necessary evil. In support of the latter approach, an interviewee claimed that,

it isn't honest to hire people only for the summer and then to kick them out because you belong to the founders of the cooperative. In case someone enters the cooperative that would be for good, they would enjoy equal rights and if a member does not fit, the cooperative can let them go. (Int.30)

Despite the different opinions expressed, empirical evidence shows that exit procedures are rarely prepared unless they are needed. Internal disagreements, health problems or other personal issues have led members to voluntary withdrawal. Nevertheless, the case of Pagkaki, of which the internal problems between 2013 and 2014 divided the cooperative into two teams and led five members to withdraw, is able to show that it is precisely that point at which members' (individual) incentives are transformed into the cooperatives' (collective) procedures. ${ }^{5}$ In particular, the fruitful discussions in the aftermath of the conflict, led the members to re-negotiate the

5 Serious internal problems emerged in some of the cooperatives studied. Some of them did not have any exit procedures, while others claimed they did. Unfortunately, reality showed that in both categories, problems could not be easily solved, putting at risk the existence of the cooperatives. The end of the official field research period did not allow the careful study of these examples and for this reason we do not elaborate further. 
identity of Pagkaki and to draw clear lines that might lead to the purposeful dismissal of a member; indicatively: disrespect to the collective's basic values, non-participation in the Pagkaki's political actions, lack of punctuality in terms of shifts and assemblies and behaviours that may harm the cooperative (for a detailed account see Pagkaki, 2015). At the same time, the members pointed out that the hasty incorporation of new members was among the main reasons for this disorder, something that forced them to clearly determine exit as well as entry procedures. More specifically, each potential member should first agree with Pagkaki's basic principles and be able to serve a specific number of shifts per week, in order to acquire substantial knowledge of the cooperative's operation. What follows is a trial period of two years. During this time, the candidate enjoys equal rights and responsibilities with the rest of the members. After six months and again after one year, the candidate evaluates and is evaluated by the assembly. In case there are complaints, the candidate withdraws since they are not formally considered a member of Pagkaki yet (Int.49; Int.50).

\subsubsection{Networked Cooperativism}

Learning from mistakes is an ongoing process that self-managed cooperatives in Greece undertake. It is also an important element that points out the dynamic character of these structures. Being among the very first self-managed cooperatives in Greece, Pagkaki communicates its experience and the steps prior to and after its establishment to other collectives, and also shares its knowledge on the reconciliation process, following a period of internal fights. Having stressed the dynamics of the emulation mechanism in transforming the individual incentives to collective procedures of entry and exit, we turn our attention to the coordinated action mechanism that helped the enlargement of boundaries in the social movement scene of labour.

Tilly and Tarrow define the mechanism of coordinated action as 'two or more actors' engagement in mutual signaling and parallel making of claims on the same object' (2015, p. 31). Sometimes referred also as "new coordination", the mechanism of coordinated action usually emerges due to the combination of brokerage and diffusion mechanisms, when the connection of actors and the spread of practices join forces (McAdam et al., 2001, p. 150; Tilly and Tarrow, 2015, p. 102). Brokerage and diffusion are also important mechanisms, concerning the social movement scene of labour. However, we argue that it was the emulation mechanism that enabled the adoption of practices and culture found in traditional SMOs, and their 
subsequent adjustment in the labour marker, where coordinated action took place. In this context, the mechanism of coordinated action matches Diani's modes of coordination, in the sense that social networks are not only the precondition for collective action to take place, which then lead to interactions, but they are also the outcome of the interaction of different actors (Diani, 2015, p. 198).

Providing support to movement-oriented cooperatives was among the main aims of the cooperativist trend, already from the early steps of Sporos collective, Pagkaki's ancestor, in 2005. Additionally, Germinal café, the first established self-managed cooperative in Thessaloniki, hosted many discussions on self-management and also tried to promote the establishment of other cooperatives. An important example here is the fact that Germinal "lent" one of its members to aid the establishment of Belleville Sin Patron café. Subsequently, Belleville proved to be a helpful source for information sharing, since it supported the first steps of Vio.Me workers towards self-management (Int.25) and assisted the formation of other cooperatives (Int.44). In Athens, respectively, Pagkaki supported the first steps of Youkali by providing economic support and consultation on the latter's legal form (Int.48). Two years of research on legal information, internal procedures and potential difficulties in some Athenian self-managed cooperatives prompted the establishment of Oreo Depo cooperative, while Akivernites Polities is considered as the twin brother of Ekdosis ton Sinadelfon in Athens, due to the strong bonds that characterize the two publishing houses. Sharing of information was among the main reasons that enabled the increase of cooperative structures, and in many cases led to their subsequent connection.

Apart from the transition of knowledge from one group to the other, coordinated action was also the result of more collective efforts. Grassroots agricultural markets, festivals on commons and solidarity economy and fairs organized by SMOs, often attracted a number of cooperatives. By bringing them into a public setting, exposing their work and fostering the further connection among them, these small events were important for the cooperatives' diffusion. Cooperatives started to form an informal category, where the worldviews for justice and equality were attempted to, through an equal share of the decision-making processes, decent working conditions and even remuneration among the members. At the same time, social cooperativism became a state law in 2011 and was met with institutional endorsement by left-wing parties, SYRIZA, Synaspismos Rizospastikis Aristeras (Coalition of Radical Left) included, as a viable alternative to the economic crisis. These were among the factors that boosted the first steps of the category formation mechanism and increased coordination among the cooperatives. 
Cooperativism does not only stand for equal participation in the internal proceedings of a collective; it also reflects a broader desire amongst these small groups to connect with each other. In this context, the "Festival on Self-management" in Thessaloniki (Festival on Self-management, 2012) that started in 2012, aimed to establish a network of cooperatives that would allow their coordination and help them deal with practical needs, such as transportation, storage and the exchange of resources. However, the lack of respective experience, the early stage of cooperatives' development, and some political disagreements led this attempt to fail (Int.21; Int.25). Similar attempts took place over the years, with the latest occurring in the aftermath of the "Second Euro-Mediterranean Workers Meeting" (Trespass, 2016; field notes, Thessaloniki, 2016) in Vio.Me factory in October 2016. Despite the international character of the event, a number of domestic cooperatives came in contact with each other and set the foundations for the organization of the Coopenair Festival, the largest annual festival of self-managed cooperatives in Greece.

Although the first attempt of networking in Thessaloniki was not successful, the Coopenair Festival brought together cooperatives from across Greece and aimed to establish a nation-wide network. The long geographical distances set barriers to the cooperatives' communication and triggered discussions on which mode of coordination better serves their goals. However, smaller networks seem to have overcome these difficulties. The successful example of the "Network of Cooperatives" (henceforth NoC) in Athens, indicates how the coordinated action mechanism constitutes a critical component within the organizational structure of the labour social movement scene.

NoC was established in the summer of 2012, due to the attempt of some cooperatives to promote self-management, coordinate their actions and help each other overcome their operational difficulties. Apart from the members' anti-hierarchical relationships, equal remuneration and participation in decision-making procedures, NoC argues against the dependent labour relations, such as having employees and individual ownership. For NoC, membership is attached to employment status and vice versa; this means that workers of the cooperatives that participate in NoC should also be members of these cooperatives, and that members should also be workers. Cooperatives in NoC are owned by the collectives and not by the individual members, in the sense that there are no individual and personal shares (NoC, 2012). ${ }^{6}$ The monthly general assembly is the ultimate decision-making

6 See also www.kolektives.org, the official website of NoC. 
instrument; decisions are based on a synthetic approach of composition and co-modulation, while absence from three consecutive assemblies signals the removal of the cooperative from the NoC.

Among other actions analyzed in the following parts of this chapter, the role of NoC was instrumental in solving one of the main problems that cooperatives seem to confront, namely the need for labour. Confronted with the departure of half of Pagkaki's team in 2013, the cooperatives of NoC established an internal practice of "sharing" their members when needed. At that time, members from Youkali, Lacandona, and Ekdosis worked shifts in Pagkaki for more than a year, so the latter could avoid hasty entry procedures for new members. The "exchange" newcomers received equal remuneration as the members of Pagkaki, but they did not participate in its assembly, since being members of other collectives assured that they already enjoyed the right to decide upon their labour without being exploited (Int.49; Int.50). This practice also took place in other collectives of NoC when temporary labour workforce was needed. At the same time, it signals how the mechanism of coordinated action fights back against the negative outcomes of emulation and can prove advantageous in enlarging the boundaries of the labour social movement scene.

Although NoC's efforts are deemed successful in many regards, the rest of networking efforts were not. This observation led a number of cooperatives in Rethimno, Crete to reject the network type of coordination, and suggest a communitarian approach instead. Departing from a libertarian communitarian approach also met in recent examples, such as Rojava, and supported by libertarian theorists like Bookchin, the cooperatives in Rethimno collaborate with political initiatives, syndicalist associations and SMOs, hold common assemblies, participate in common actions, and share a common fund in order to serve their needs. As we see throughout this chapter, the vast majority of the studied cooperatives are actively involved in a number of political activities and consider themselves part of the broader antagonistic movement. Nevertheless, the communitarian approach suggested by the cooperatives in Rethimno, attaches by default a radical identity to cooperatives, without distinguishing them at all from the rest of the political initiatives. ${ }^{7}$

7 This project was called "proplasma", a Greek term meaning pre-creature and denoting that this community is the basis for the imaginary society. The pre-figurative and communitarian characteristics of proplasma suggest a different form of connection for cooperatives. Nevertheless, its birth came after the end of our field research, and, therefore, we could not study it in detail. 


\subsection{Resources}

We have stressed many times so far how important resources are for social movement actors in times of austerity. When it comes to the social movement scene of labour, of which the basic concern is the expansion of self-organization in the labour market and the economic survival of its constituents, resources acquire a substantive value. Resources concern the operation of the self-organized cooperatives, but also reflect the goals and means to achieve them. Respectively, inputs and outputs have an economic dimension and they also characterize the relation and interaction of cooperatives with social movements (Diani and Mische, 2015, p. 308). By looking at the initial capital, the compensation and pricing policies, as well as the audience they address regarding the demand and supply side, we explore the mechanisms and sub-mechanisms that helped the expansion of boundaries with regards to the social movement scene of labour.

\subsubsection{Initial Capital}

The need for employment and the desire to expand the values of selforganization within the labour market are the main reasons behind the establishment of self-managed cooperatives. Although the degree of application varies, these two issues are present in all the cooperatives studied and affect many aspects of their operation, also including the cooperatives' initial capital.

Starting with the former, the self-managed cooperatives are characterized by low initial capital. ${ }^{8}$ Also, taking into consideration that they are mostly funded by the unemployed or workers in a precarious employment position, cooperatives are usually labour and not capital-intensive. In this context, many cooperatives are characterized by a do-it-yourself (DIY) logic, often found in SMOs and not in typical enterprises. 'We bought very few things, like a fridge and shelves, while everything else came from the members' previous activities and stocks. The basic capital we invested was our working hours' (Int.24), argued an interviewee from Allos Tropos. Likewise, another interviewee from Oreo Depo claimed that, 'apart from the electrical and

8 Although the aim of the research and the sensitive nature of the economic issues did not allow thorough and in-depth evaluation of cooperatives' financial data and economic well-being, we were able to draw some general conclusions that are helpful for depicting their operation. In this respect, the usual initial budget of the cooperatives counts approximately between 5000 to 20,000 euros. 
plumbing installations, we did everything else on our own' (Int.30), while similar accounts have been expressed by Ekdosis ton Sinadelfon and other cooperatives as well.

Of course, low capital creates many problems, with the delays in starting-up businesses being among the most important ones. In many cases though, this delay proved valuable, as it further boosted the members' "homogenization" and bonding. Lacandona members stressed that setting their own terms in the cooperative's management was strongly linked to the collective construction of the café-grocery store. 'We set it up on our own; we painted it, we laid the tiles, we learned to do a number of things with our own hands. It belongs to us, it's totally and truly ours' (Int.49). Along the same line, among the tactics to reduce their fixed costs or to pay back the money they borrowed, some of Pagkaki members decided to live collectively before the opening of the café (Int.49). On their effort to save as much money as possible, many members of cooperatives kept their previous employment at least during the cooperative's first stages, something that urged other members to devote more time to setting up the enterprise.

The low initial level of capital is not only due to the members' strained economic means, but it is also subject to their political values. In their effort to stand on their own feet, cooperatives try to have as little dependency as possible on institutional actors. In line with this argument, NoC urges its members to avoid potential affiliations with, and funding from, the Greek Orthodox Church, political parties and other institutional actors (NoC, 2012). Rather debatable in this context for NoC's members, is the European funding coming from National Strategic Reference Frameworks (NSFRs). Some cooperatives, like Pagkaki, automatically reject this type of funding, but appear to be more susceptible to absorbing funds from the national unemployment association or the social insurance agency (Pagkaki, 2015). Other cooperatives, like Ekdosis ton Sinadelfon, embrace a skeptical stance towards NSFRs, but without rejecting them by default, while other cooperatives, such as Lacandona, received funding from NSFRs, arguing that it was 'very crucial to relieve the burden from the internal loan' (Int.45). Similar approaches can also be found outside of NoC, with some cooperatives clearly willing to receive it (Int.30); others not contesting the possibility to review their initial negative decision (Int.21; Int.19); and finally, some cooperatives that fully rejected it by arguing that they 'did not want to become anyone's alibi' (Int.24).

An interesting juncture with regards to the initial capital, where the need for employment meets the political character of the cooperatives, can be found in the entry requirements. Among the innovative characteristics that 
Pagkaki and Germinal brought to the social movement scene of labour, was the fact that lack of capital did not prevent people from getting involved in the cooperatives. The project of Germinal collective was a product of discussions within the Libertatia squat; after the decision of Germinal's establishment was achieved, its members issued a call for the participation of the rest of the squatters, regardless of whether they could contribute to the initial capital or not (Int.25). The same applied to the Belleville cooperative, where only two out of six initial members contributed financially, with the rest participating equally in the cooperative's operation. According to an interviewee,

this is the collective's social character, that you don't need capital to become our colleague. [...] It was also a way to support people that were unemployed to create something of their own. Otherwise, it would be just a civic capitalistic enterprise, a civic cooperative. That's exactly what we wanted to overcome. (Int.25)

In the same vein, Pagkaki's members argued that since the initial capital was amortized in the first two years, there was no need for the newcomers to financially contribute. Many cooperatives' members argued that asking for a newcomer to contribute the same amount of money as the rest of the members did, in the beginning, improve the sense of equality among the workers. Commenting on that, a member of Pagkaki claimed that 'since the initial capital was amortized, we don't want money to represent commitment and equality in our collective' (Int.5o). Instead, potential newcomers are consulted to devote some extra 40 hours to political duties as a way of symbolically compensating the effort of the first members.

The path paved by Pagkaki and Belleville has been followed by many cooperatives, without avoiding differentiations. The members of Ekdosis ton Sinadelfon contributed unequally to the initial capital and worked voluntarily during the first five months, in order to pay back their internal loan, while the absence of shares indicates that no initial capital is required for new entries (Int.23). Similarly, the desire to be as close to equality and equity as they could, urged the members of Akivernites Polities to argue that, 'we are neither employees nor employers, we are not shareholders, we do not have $20 \%$ of the cooperative each, we cannot bequeath, sell or transfer our part of the cooperative' (Int.31). The case of Oreo Depo is different, as its members ask newcomers to symbolically contribute at least fifteen euros to acquire one share which will be given back once amortized, although the amount is not bound to the assembly's votes (Int.3o). Nevertheless, the 
unequal initial contribution or the absence of a capital requirement in the potential entries are not always considered valuable. Although members of Domino café cooperative share equal rights and responsibilities, the unequal contribution in terms of initial capital and members' working hours during the construction of the cooperative, gave a different leverage regarding the demand of working shifts once the cooperative began its operation. So far, the varying degrees of effort seem to be respected by all the members in the cooperative and no problems have arisen; but as an interviewee stressed, that decision was quite risky, and it could prove rather problematic (Int.21). That was for instance the case for Youkali cooperative. The cooperative's policy of not asking initial capital from the newcomers created tensions until its amortization. As one member noted, 'we didn't have the same goals; the guys were stressed because they wanted to take their money back, meaning automatically that in some occasions you should back off' (Int.48).

Although the legal self-managed cooperatives are subject to variations regarding their initial capital, no initial capital is required for the newcomers in the self-managed structures operating within social centres. As active components of the centres' general assemblies, the self-managed structures have their own assemblies, but are unable to move away from the central value system. In addition to this, attendance to the social centres' general assemblies are amongst the pre-requisites for participation (Int.51). As an act of compensation, in cases like the Mikropolis social centre, the members working in the self-managed structures are required to voluntarily work three hours per week in the social centre's bar, which is the centre's main resource (Int.34). Usually, self-managed structures have their own separate repository and manage their finances independently from the social centre. However, it is quite important that when it comes to initial capital, in most cases it is the social centre that provides an unofficial internal loan to the structure, which is gradually payed back by the latter's surplus.

\subsubsection{Compensation, Demand and Supply}

The aforementioned examples demonstrate a variety of practices applied, aiming to merge the members' political beliefs with the need for employment. No matter their differences, success or failure, all of them witness the desire of cooperatives to create equal working conditions. To this end, the different ways of compensation consist also of an additional tool for achieving equality in the working space. Most of the cooperatives apply a shift-based approach, through which each worker is paid according to the monthly working hours. However, there are also cases, like the one 
of Lacandona, in which members receive equal monthly compensation, regardless of their working hours (Int.45; Int.47). In order to achieve the maximum degree of equality, cooperatives apply a rotation system, with each member undertaking different tasks. Although the rotation practice can be widely applicable, it is not always possible. This is the case, for instance, with Ekdosis ton Sinadelfon publishing house. Ekdosis ton Sinadelfon members preoccupied with wholesale and retail sales work the same shifts and receive the same salary, but the production and publication of books involve different tasks, such as editing, graphic design, etc. In order to find an adequate way to evaluate the amount of money for members serving different tasks, the cooperative takes into consideration the market value of their labour and adjusts it accordingly to the respective market value of the rest of the members (Int.23).

The self-managed structures within SMOs exhibit a different approach. The three self-managed structures of the Mikropolis social centre, namely the grocery store, the collective kitchen and the bookstore, collect their different surpluses and distribute them equally to all the members. As an interviewee noted,

every six months there is an opening in case more people want to participate in the structures, presupposing they are already members of Mikropolis. In case someone is interested, then the older member should leave, since our approach is based on social ownership, meaning that structures do not belong to anyone. (Int.34)

On the other hand, the three respective self-managed structures operating in Sholio squat do not share a common repository, but each member is paid according to the surplus of the structure that they participate in. This risks the potential of increasing the competition among the members to join the most profitable structures. Nevertheless, participation in Sholio is a prerequisite for participation in any of the structures, and therefore, secures that members share common values and ideological beliefs. In this respect, according to an interviewee, common participation prevents the rise of competition, and on the contrary, motivates members to further develop the respective structures they participate in (Int.51).

Despite the different approaches applied within the official self-managed cooperatives operating in the capitalist market and the unofficial cooperatives within social centres, both categories demonstrate that members of the self-managed cooperatives do not act as typical businessmen. This becomes quite evident when it comes to the pricing policies and supply procedures. 
Cooperatives not only suggest a different model of management, but they also advocate for economic moralization. Instead of applying a profit-driven logic and acting as transformative instruments, which buy cheap and sell expensive to make a profit, self-managed cooperatives act as equalizers between producers and consumers. In particular, they try to secure decent labour conditions and fair prices both for their suppliers and themselves, without decreasing the quality of their products and services. This approach mirrors some features often found in the consumerist movements of the global North and the solidarity trade in support to the global South. As is the case in social clinics, resources are not pictured only as a means of mobilization, but also as vehicles of solidarity in practice. The development of ties between different struggles through resources reflects the mechanism of in-group brokerage.

Earlier we defined in-group brokerage as the 'connection of factions and groups on each side of an "us-them" boundary without establishing new connections across the boundary' (Alimi et al., 2015, p. 287). In the context of cooperatives, in-group brokerage refers to the "supply side", which connects them to other cooperatives and alternative grassroots endeavours. Diani (2003a, p. 7) distinguishes between direct and indirect ties: the former point to personal relationships on an individual level or the coordination for the promotion of a common goal on an organizational level; the latter describe cases in which organizations share members, sympathizers or resources. We argue that the development of in-group brokerage in the factor of resources manages to merge direct and indirect ties. The mechanism is quite complex and may unfold through different channels, depending on the content and services that each cooperative provides. In the cases of Perisilogi ${ }^{9}$ producers' cooperative and Vio.Me, which are built on the model of integrated cooperatives where every aspect of their operation takes place within the cooperative, in-group brokerage concerns the supply of raw materials. Since most cooperatives are formed as grocery stores, cafeterias, bars and taverns, we turn our attention mainly to the food and catering sectors.

Starting with in-group brokerage, self-managed cooperatives try to support similar efforts, by supplying their products from cooperatives in Greece and abroad. 'We mainly distribute products from cooperatives. When we cannot find cooperative products, we turn to small industries which we know have good labour conditions and quality products' (Int.26), argued an interviewee from Eklektik café-grocery, while Oreo Depo supplies

9 Perisilogi stands for self-reflection but also implies the collection (sillogi) of agricultural products. 
'Latin American coffee from Svoura collective, LiberoMondo tea from Bios consumer cooperative, the Zapatista coffee from Allos Tropos' (Int.3o). Additionally, a Lacandona's interviewee noted that,

we prefer to call it solidarity and not fair trade, since trade can never become fair! Apart from the products of solidarity trade that come from the countries of the South, we are interested in abolishing the division between north and south. In order to achieve this, we chose to distribute products from cooperatives and small producers in Greece as well. (Int.45)

The case of Vio.Me is rather important here, since the factory does not operate in the regular market and does not collaborate with big supermarket retailers. Rather, it distributes its products solely through the solidarity networks of cooperatives, squats and social centres (Malamidis, 2018).

Due to the criteria established by cooperatives regarding the labour conditions their suppliers provide for their employees and the quality of the products they receive, in-group brokerage stands as an additional mechanism for the social appropriation and diffusion of self-management principles to small producers. This way, resources are the spearhead for the connection among cooperatives, as well as for the diffusion of their organizational practices and the culture of self-management. Thus, in-group brokerage can prove to be quite helpful for the economic survival of many cooperatives, but at the same time it might have devastating effects on those who do not comply with the criteria set by the cooperatives. Poor labour conditions, dismissals of employees and poor quality of the products caused cooperatives to stop collaboration with specific suppliers many times, while instances of revelation that some producers were Golden Dawn's supporters immediately ceased any transaction. Equally important, in-group brokerage stands crucial for the dissemination of relevant information among the cooperatives, something that can prove to be both highly advantageous and disastrous for the suppliers.

Apart from the individual cooperatives, the mechanism of in-group brokerage also operates on a collective level. Together with the members' exchange, cooperatives in NoC distribute each other's products. Thus, Pagkaki sells the books of Ekdosis ton Sinadelfon, Ekdosis ton Sinadelfon sells Zapatista coffee from Synallois cooperative supermarket, etc., connecting in this way their wellbeing to each other's. Similar examples can be found outside of NoC. For instance, Perisilogi producers' cooperative distributes its products through the local market without middlemen and Allos Tropos members participate in the Koukouli cooperative grocery store (Int.22). Despite keeping our focus mainly on food and catering, we observe that 
similar paths of in-group brokerage are followed in other sectors, with digital cooperatives supporting open software, digital commons and alternative cyber communities, or Ekdosis ton Sinadelfon and Akivernites Polities developing ties with small and alternative publishing houses.

Supply is only one side of the coin, since, as economic entities, cooperatives also deal with the side of demand. Although cooperatives are supported by activists, according to the interviewees, they reach a far broader audience from different social and political environments. The same also goes for the cooperative structures within social centres. In this respect, pricing policies and practices of socialization are the connective elements between the sides of supply and demand.

Following the logic first introduced by the grocery store of Sporos collective, self-managed cooperatives try to achieve fair prices for producers and consumers.

We have a stable 25 per cent profit over the grocery store's products. Our aim is that basic products should be economically accessible to the lower strata. Nevertheless, there are other products which are subject to a different logic, meaning that consumers will also express their support in a way (Int.26),

argued a member of Eklektik. Nevertheless, the tremendous reduction of the population's purchasing power, together with the continuous introduction of new taxes, created serious obstacles in the fair-prices policy. Cooperatives responded to that in various ways. Pagkaki, for instance, expressed publicly that it will absorb the crisis' consequences by arguing that 'when the consequences of the rapid impoverishment reached us as well [...] we did not choose to downgrade the quality of our products, [...] to increase our prices, [...] to extend our shifts, but to lower our wages' (Pagkaki, 2015). In a similar vein, Perisilogi producers' cooperative chose not to calculate the members' cost of labour on the products' prices, but to add a specific percentage to the cost of the raw materials instead; otherwise, the final price would be very high (Int.22). Reflecting on this, a member from Youkali café argued that,

we are supplied our products from small producers, our coffee from Synallois cooperative supermarket and tea from Lacandona. When you want to keep prices low, as in our case, you cannot avoid also buying commercial products. The truth is that alternative trade is very nice, products are of great quality, but they are also very expensive. (Int. 48) 
Another interviewee from Oreo Depo claimed that, 'since we support the concept of solidarity economy, we buy expensive and sell cheap!' (Int.3o). Research in solidarity purchasing groups in Italy reveals similar issues (Grasseni, 2014a, p. 84). Although by not having bosses cooperatives secure the non-seizure of their surplus value, these examples reveal one of the most important dilemmas that they have to deal with, regarding their economic success: keeping the quality of the products high while maintaining low prices, in order to serve the needs of the broader population, and thus decreasing the members' compensation and risking the cooperatives' economic growth; or sacrifice any of these features in favour of the others. Despite the variations in this equation, the social and political approaches of cooperatives so far seem to dominate, as opposed to larger economic growth.

Lowering the prices or adding a new member are two of the policies that many cooperatives follow, in order to socialize their profits. However, cooperatives also practice different methods of demonstrating their social character. The cooperative of Allos Tropos for example has established a grocery store, which distributes products without the intervention of brokers, while at the same time it organizes courses of chess and painting, free of charge (Int.24). Following the same approach, Lacandona organizes workshops on soaps' production or seeds' growing (Int.45), Perisilogi producers' cooperative organizes hiking tours on their fields (Int.22), while Sociality organizes seminars on software and offers consultancy services for the establishment of cooperatives (Int.28). These are only a few of the actions that cooperatives undertake free of charge as a means of socializing resources. A closer look at the cooperatives' resources, however, reveals another important aspect. Resource socialization does not only address society in general, it is also directed towards the social movement community more specifically. This is explained in detail in the next section.

\subsubsection{Investing within}

In-group brokerage and the distribution of products show how resources are used among domestic and foreign cooperatives, as a practical way to support each other's struggles. Resources are being also used in order to enhance the internal connection between various cooperatives, as well as between cooperatives and more traditional SMOs. This intermediary role of resources triggers the mechanism of out-group brokerage. Cooperatives in Athens and Thessaloniki try to establish common self-help funds in a way that supports their members in cases of emergency, but also to fund other 
cooperatives or labour-related struggles. Cooperatives have also developed contacts with the social clinics for the provision of free medical care to their members. In the same context, cooperatives are closed during strikes, with their members participating in the demonstrations, while in some cases, the surplus of the nightshifts on strike days is used to fund labour struggles and grassroots unions. Similar practices were rather widespread in the labour movement and its respective organizations (Gall, 2010; Katsoridas, 2016; Williams, 2016); nevertheless, these are still under development with regards to the self-managed cooperatives in Greece.

What seems rather important, however, is that self-managed cooperatives are transformed into resources for the broader social movement community. In particular, cooperatives have developed a dual relationship with the movement community, in the sense that they both serve as resources, but also as sources for new resources. 'We were also thinking that this space could serve as a meeting place for the city's movements' (Int.45), argued an interviewee from Lacandona, revealing a view that was often promoted by other cooperatives. Similar to what many social centres do, Lacandona's space hosts the assemblies of political collectives and initiatives, Oreo Depo hosts the assemblies of other cooperatives, while the same is also expressed by Poeta, where members of the extra-parliamentary Left, 'like ANTARSYA (Anticapitalistic Left Cooperation for the Overthrow) and LAE (Popular Unity), hold their assemblies here and sometimes also groups from the anti-authoritarian space' (Int.44).

The spatial characteristic of cooperatives is an important element for out-group brokerage, something that is also fostered by the distribution of activist material from their premises. Like other cooperatives, Belleville has established a small bookstore, where 'political and movement-oriented books are sold at cost price and aim to promote a certain logic' (Int.2o), while it also distributes brochures, leaflets and books published by SMOs, which cannot be found in commercial bookstores. Together with written material, cooperatives distribute T-shirts as well as vouchers issued for the financial support of SMOs. The increased flows of refugees in the summer of 2015 forced many cooperatives to become collection points for food, clothes and medicines. 'We were collecting stuff for Idomeni from the first moment' (Int.3o) commented an interviewee from Oreo Depo, while Lacandona supplied the unofficial refugee camp of Pedion Areos park and Dervenion refugee squat in Athens (Int.45).

To some extent, cooperatives managed to organically build connections with the movement community. In a way of sharing its audience with social centres and squats, Ekdosis ton Sinadelfon hold many of their 
book presentations in SMOs. Most importantly, Ekdosis ton Sinadelfon has decided from day one to distribute its books to social centres and squats with $50 \%$ discount on the original price (Int.23), while Akivernites Polities have supplied the bookstores within SMOs at cost price (Int.31). These two policies are rather crucial source of resources for SMOs, since they are the ones to set the final price of the books. Thus, one squat may sell an Ekdosis ton Sinadelfon book at the same price as the publisher, but it is the squat that will enjoy the $50 \%$ profit. Using a similar logic, Sociality offers its "premises, infrastructure and "know-how" to different collectives, to help them to create (digital) calendars or to promote movement-related events' (Int.28). In this respect, the cooperative has also produced the digital coordinating platform for the markets without middlemen in open source code and implements different pricing policies for SMOs and movement initiatives (Int.28).

The mutual-aid funds that cooperatives implement are the offspring of the labour movement, while the distribution of movement material or the provision of spaces for assemblage, is something mostly found in SMOs and not in enterprises. These incidents show that emulation constitutes a great component of the out-group brokerage mechanism, as the practices are transferred and applied from one movement scene to another. Since financial contributions in times of austerity are valuable and highly appreciated, the sub-mechanism of emulation presents another practice which further strengthens the development of the out-group brokerage mechanism. This practice refers to the "financial contribution nights" or the so-called "red shifts".

The organization of parties and events dedicated to raise funds for a specific cause is probably one of the most common practices of squats and social centres worldwide. This repertoire has been largely welcomed by the cooperatives, which dedicate the surpluses of specific days to support different struggles. How are these red shifts organized? One can identify two paths: either the cooperative "lends" its premises to a collective responsible for the event with the latter's members providing their services, as happened around 40 to 50 times in Belleville (Int.25); or the event is organized by the members of the cooperative, who are also in charge of working during the event, as is the case of Pagkaki (Int.5o). In both cases, shifts are unpaid, and surplus is given to a specific initiative which the event is dedicated to. This varies from the support of cooperatives, as was many times the case for Vio.Me, Poeta, Akivernites Polities and others (Int.25); emerging squats or self-managed enterprises and factories, like the timber plant of Roben in Veria (Int. 48); political and social initiatives, like the assembly of the 
unemployed in Autonomous social centre (Int.48); or for the coverage of activists' medical expenses (Int.44; Int.25).

Red shifts are not only important for the financial support of cooperatives and SMOs, but they also have a particular significance for the overall process of boundary enlargement. Although emulation suggests the repetition of performance in different settings (Alimi et al., 2015, p. 288), red shift practices do not just multiply the potential sources for movement resources, but they actually expand them in new settings. To put it simply, red shifts do not recycle resources within the movement community, but since cooperatives reach much more diverse and wider audiences than traditional SMOs, the overall financial capital of the movement community is increased. Similar to the concept of transvensment discussed in the commons literature, cooperatives transfer resources from the capitalistic market to the movement community, which are then re-invested in producing similar and new projects. In these terms, movement resources seem to gradually enlarge their own boundaries and reflect what in the literature of commons and solidarity economy is often described as "generative commons".

\section{$5 \cdot 3 \quad$ Identity}

The previous sections indicate how self-managed cooperatives are formed with respect to the factors of organizational structure and resources. In line with the contentious politics approach, these factors are not static; instead, due to the cooperatives' experimental approach, their characteristics are dynamic and evolve in relation to their internal procedures and external environment. The cooperatives' pre-figurative approach provides both an instrumental (objective) and an experiential (subjective) element to their organizational model and resources, reflective of their identity. Due to this, the emulation sub-mechanism identified in the two previous factors, declares that signs of path dependency contributed to the passage from self-organization to self-management; from the social movement community to the social movement scene of labour. Simultaneously, the development of the social movement scene of labour included diversifications, with some cooperatives arguing for aggressive and others for defensive approaches to self-management. In our effort to dismantle the development of the self-managed identity, this section investigates the mechanisms which explain the origins of self-managed cooperative culture and points out the main forces surrounding the cooperative spirit. 


\subsubsection{Contentious Origins of Self-management}

Although the social movement community in Greece was relatively active and vibrant before the advent of the crisis, the same cannot be said about the scene of labour. As many inquiries witness, Greece is a country with a strong tradition of hierarchical and paternalistic management structures (Bourantas and Papadakis, 1996; Kritsantonis, 1998; Marcovitz et al., 2007; Psychogios and Wood, 2010). Kioupkiolis and Karyotis (2015) inquiry on self-managed initiatives refers to a dozen of industries dating back to the 1980s, with workers actively involved in their management, and in some cases running their factories on their own. Despite the qualitative differences of participatory models such as "co-management", where the workers contribute to an existing structure and system of values without the potentials to change them completely, with self-management (Katsoridas, 2016, pp. 18-22; Kokkinidis, 2012, 2015), the absence of supportive movement networks, as well as the workers' ambition for the enterprises' nationalization, were among the factors that led to the collapse of these endeavours (Katsoridas, 2016, pp.105-126; Kioupkiolis and Karyotis, 2015). With the hierarchical tradition of management on the one hand, and the noticeable silence of the movements' involvement in self-management on the other, one question that arises is how the idea of self-management became so popular in a context where it has not been part of the historical tradition.

McAdam et al. (2001, Chapter 2) analyse the difficulties in understanding contentious origins through the usual agenda of social movement studies. Instead, they argue (Ibid, Chapter 3 and 4) that by decomposing the events into mechanisms, one can understand the dynamic trajectories at play. In this context, we argue that the origins of the social movement scene of labour were a result of the combination of four mechanisms, namely appropriation, legitimation, certification and diffusion.

Similar to the appropriation of black churches in McAdam's et al classic example (2001, pp. 40-44), self-management and cooperativism in our case have been appropriated both conceptually and practically. McAdam, Tarrow and Tilly note that 'appropriation paves the way for innovative action by reorienting an existing group to a new conception of its collective purpose. But for the initial mobilization process to be fully realized, this disposition to act must be translated into innovative collective action' (2001, p. 316). Although our explanation does not deal with mobilization per se, our discussion proves that appropriation takes place in other processes as well. Chapter 2 briefly outlined how Pagkaki and Germinal collectives started their operation in 2010. The establishment of these two collectives at the same 
time was a clear product of coincidence, since none of them were aware of the other's efforts (Int.25). ${ }^{10}$ Nevertheless, both cooperatives were outcomes of political discussions within the assemblies of self-organized collectives. 'As a prerequisite for action', McAdam argues that 'would-be-insurgents must either create an organizational vehicle and its supporting collective identity or, more likely, appropriate an existing organization and the routine collective identity on which it rests' (2003, pp. 291-292). Without a tradition to refer to or appropriate, debates within collectives dealt with the limits of self-organization in political collectives, and the way that this type of participatory management could be introduced in everyday contexts, such as the environment of the labour market.

Around two years before the establishment of Germinal collective, internal discussions among the members of Libertatia squat concluded that self-management is the answer to the neoliberal crisis. The members argued that history is full of failed examples of small and individual self-managed efforts that were absorbed by the neoliberal market. However, the diffusion of self-managed laboratories has revolutionary dynamics, which can create spaces that will not re-produce the dominant logic of development; instead they will "train" people in the libertarian ideals (Int.25). Half of the squat members came to realize these accounts through Germinal cooperative. As they supported in the collective's founding declaration, Germinal was born out of frustration with their previous precarious labour conditions and also because it was time for action. In the members' words, 'it is not enough for us to declare our denial and reaction towards the world of bosses. It is time to experiment with our own self-organized, anti-hierarchical, self-managed structures on the issue of livelihood without bosses. We move from theory to practice' (Germinal, 2012). Unfortunately, financial difficulties forced Germinal to cease operations two years later. In the meantime, the collective has attracted and consulted many people interested in setting up similar endeavours. As such, some of its members got involved in the establishment of Belleville and Domino self-managed cooperative cafes in 2011 and 2013 respectively.

Although theoretical debates were also present prior to Pagkaki's establishment, the birth of the cooperative took place mostly due to the practical dilemmas in the ancestor collective of Sporos. The international solidarity movement to the Zapatistas in the late 1990 s and the common interest in

10 Lack of information has been met in many organizations and constitues one of the main reasons that caused cooperatives to undertake different trajectories observed in the social movement scene of labour. 
Latin American struggles, led a group of activists in Athens to order and distribute Zapatista coffee by hand. Gradually, this network started to expand, and in 2005 the self-organized collective of Sporos inaugurated its premises in Exarcheia, as a way of economically supporting the Zapatistas struggle. Quite soon, Sporos got engaged in many political initiatives dealing with genetically modified organisms (GMOs), natural cultivation of seeds and de-growth, something that led the collective to distribute the products of movement-oriented Greek cooperatives and to establish a clothing barterclub (Varkaolis, 2012). Although it had a legal status of civic cooperative, its 25 members used to hold unpaid shifts in the collective once per week. In this sense, Sporos was probably the first political group that tried to promote solidarity economy in Greece, formed under the principles of direct democracy and horizontality. As one interviewee argued,

when I entered Sporos I was 20 years old and although I was active in anarchist collectives, it was there where I joined some discussions for the first time in my life. Sporos members came from different political backgrounds but in reality, all of them were part of this new trend; the one prompting that apart from arguing against the state and capitalism, we should see what we should do here and now. (Int.49)

Despite its success, Sporos' operations ceased in 2012, while the project continued under the same model of operation by another collective named Svoura. ${ }^{11}$ The lack of passion during the assemblies and the internal disputes were amplified by the members' different perspectives on labour (Varkaolis, 2012). The great increase in Sporos' turnover required the members to devote a lot of time, with some of them posing the issue of receiving compensation and others insisting that the political role of the collective should be strictly voluntary. As an interviewee noted, 'it is one thing to participate in a social centre and a completely different thing to be in a shop with high turnovers and no one getting paid. An enterprise with great demand that required extensive commitment from its members and worked well' (Int.49). At that point, the absence of unanimity prevented the members from proceeding further with self-management. Nevertheless, by 2008 , the continuous discussions had inspired eight of Sporos members to develop the plan and open Pagkaki in 2010, and others to form the cooperative supermarket of Synallois in 2011. 
Through the lens of the resource mobilization approach, both Sporos and Libertatia squat served as pre-mobilization structures that fostered the idea of self-management. However, this static understanding would miss much from the evolution of trajectories of these first self-managed collectives. McAdam et al. argued that, 'instead of pointing to pre-existing mobilizing structures, we call attention to the active appropriation of sites for mobilization' (2001, p. 44). From this perspective, we move towards a dynamic approach to structures, which recognizes the different powers that interplay in the path from point $A$ to point $B$, which, in our case is translated from self-organization to self-management. As such, both Sporos and Libertatia can be seen as vehicles that served to ease, both practically and theoretically, the appropriation of the sites of labour by the social movement scene. The mechanism of social appropriation is rather important since, on the one hand, the application of the movements' self-organized principles on the labour scene helps the development and diffusion of selfmanaged collectives; while on the other hand, it serves to fill the country's cultural void of self-management.

Of course, the path towards appropriation was not paved with roses, and diffusion has not been set in motion automatically; rather it was through the intervention of the legitimation mechanism. As Alimi et al. put it, legitimation stands for 'the generation of favorable and resonating representations of a SMO' $(2015$, p. 56). In our context, the traditional de-legitimation of economic activities within and by SMOs started to reverse. Apart from the internal disagreements we referred to earlier, fractions of the movement community accused Sporos and Pagkaki of supporting the logic of consumerism and trade (Int.49). The same also happened with Germinal, with an ex member arguing that,

I am not sure how "legitimized" it (the logic of cooperativism) is nowadays within the movement community [...] but we received tremendous criticism since we were against the culture of anti-commercial and money-less transaction; they accused us of making money out of it and that these ideas were parochial. (Int.25)

The continuous publication of informative material regarding the actions and theoretical approaches of Pagkaki and Germinal were accompanied by the simultaneous organization of festivals and events, such as the "Creative Resistance Festival" (Varkaolis, 2012, pp. 37-41); Second anti-consumerist, 2008), as well as by the international experience of Zapatistas and the movement repertoires during the Argentinean crisis of 2001 (Int.49). 
Legitimation also came from a number of social centres that started to introduce self-managed practices within their operation. In their search for a larger space, the members of Buenaventura social centre squatted an abandoned school in Thessaloniki in 2010 under the name "Sholio". Since they were in Buenaventura, the members of the collective were already arguing for the free dissemination of knowledge through the provision of free courses and alternative forms of teaching. However, once the theoretical quest blended with the practical difficulties of austerity, the situation urged Sholio to set the promotion of solidarity economy as another central goal. In particular, the relatively cheap food provided by the Sholio's members' collective kitchen, combined with broader economic distress, and the flight of many of its members outside Thessaloniki to seek employment, encouraged the general assembly to transform it into a collective self-managed structure and introduce compensation for the members in charge (Int.51). Together with its members working in the collective kitchen, Sholio also provides compensation for the members working in its brewery and grocery store, as a way of practically promoting its approach to solidarity economy. This decision created internal tension and led some of its members to withdraw, arguing about the anti-commercial logic of squats. Sholio continues to receive criticism by many SMOs, regardless of the collectives' absence of any legal status or tax registration. Nevertheless, the introduction of compensation for certain tasks has been adopted by other social centres as well, stabilizing the mechanism of legitimation in terms of solidarity economic practices.

Our data so far suggests that the appropriation mechanism came to be followed by the legitimation of self-managed practices. Although these mechanisms are ordered sequentially, the same cannot be said for another set of mechanisms that followed. In particular, the mechanisms of diffusion and certification are intertwined with one feeding back the other. In order to clarify this, we first turn our attention to the mechanism of diffusion.

The mechanisms developed in the factor of resources show that many cooperatives have developed strong ties amongst themselves. Nevertheless, their vast expansion both in terms of organizational practices and cultural artifacts, were due to the diffusion mechanism and not brokerage. According to McAdam, 'diffusion requires a much lower investment in time and entrepreneurial energy than brokerage' (2003, p. 296). Diani argues that 'typically, social movement activists and sympathizers are linked through both "private" and "public" ties well before collective action develops' (2003a, p. 12). Direct ties such as friendship or shared participation in movement activities, and indirect ones like joint involvement in specific activities 
and/or events, yet without any face-to-face interaction' (Ibid), usually consist of the antecedent conditions that affect the creation of individual networks. Building on that, we argue that political and social homogeneity are significant components of the diffusion mechanism.

Political homogeneity refers to a population bound with strong political affiliations and experience in participatory procedures; while social homogeneity points to a group of friends and familiars, who share experience in similar working environments (Table 5.1). ${ }^{12}$ In the case of Germinal, Libertatia squat helped create a shared understanding on how assemblies function, whilst the members' previous work experience in the catering business proved to be decisive for establishing the café (Germinal, 2012). The same applies also to Pagkaki, of which the experience in Sporos and their shared will to work collectively encouraged the members to prefer the option of a coffee shop (Int.49). Being the pioneers, Pagkaki and Germinal have every characteristic included in Table 5.1, which was not always the issue for the self-managed collectives to come.

Ekdosis ton Sinadelfon started as an unofficial political intervention by four friends in 2009 to the workers' union in publications and bookstores, by publishing material regarding the Argentinean crisis. Three years later, while being unemployed, more people joined in through their personal networks and opened the cooperative bookstore, suggesting self-management as a different approach to labour (Int.23). Conversely, the respective effort of Akivernites Polities in Thessaloniki 'started as the union's idea to create its own bookstore in order to deal with the sector's wave of layoffs and unemployment' (Int.31). Although the union did not realize its plan, five of its members discovered it in October 2013, when they became unemployed. Membership in unions was common, but neither friendship nor political origins were. The passion of Lacandona's members

Table 5.1 Political and Social Homogeneity

\begin{tabular}{lll}
\hline & Political Characteristics & Social Characteristics \\
\hline Ties & Political Relations & Social Relations \\
Experience & Collective Procedures & Sector of Occupation \\
\hline
\end{tabular}

12 To avoid any misunderstandings, it is important to note that we use the term homogenization in a generic manner, since ethnographic inquires and in-depth case studies may reveal that members of the organizations share quite diverse theorizations. The empirical chapters of this book discuss such instances, where the different views resulted from internal disputes and up to the dissolution of organizations. 
for solidarity trade coincided with poor working conditions in their former employment and urged them to quit and establish their self-managed café-grocery store in 2011 (Int.45). Although these examples denote the members' close relation with the ideas of self-management, other examples witness its diffusion towards more peripheral parts of the social movement society. The café-bookstore Poeta and the café-tavern-grocery store Oreo Depo in Thessaloniki are exemplary cases. Established in February 2014 and April 2015 respectively, they shared the members' precarious working conditions and dreams for bohemian cafes with quality products and respect for the workers. In both cases the members were politicized, but without participating in SMOs, they knew each other through their personal social networks and had either minimum (Oreo Depo) or no (Poeta) relative work experience (Int.44; Int.30).

These examples do not witness clear cut patterns in terms of ties and experience prior to the establishment of the collectives, but most cases resulted of a combination of some of the political and social characteristics described in Table 5.1. As we discussed in the previous section, six months up to three years mediated prior to the cooperative's establishment, facilitating the better connection of the members. Additionally, the shared trust and minimum political agreement, combined with the desire to work collectively under equal labour conditions, were factors that boosted the expansion of self-managed cooperatives. At the same time though, the relational approach of contentious politics calls us to pay attention to the attribution of opportunities and threats related to the external environment. In this context, the legislature environment triggers the last mechanism, the one of certification.

Moving to the certification mechanism, the cooperative form became quite popular since it was pictured as the most adequate form that could support the collectives' intention for self-management. The shameful past of state intervention ${ }^{13}$ and corruption scandals in the Greek cooperative movement, forced many of the first collectives to distance themselves from the traditional cooperatives and redefine themselves based on their commitment to self-management. Things changed in 2011, when a distinct legislation for social cooperatives was introduced, setting the foundations of institutional provision for social economy for the first time in the country. Under the new legislation, social cooperatives enjoyed less taxation compared to the

13 It is worth mentioning here that the state's intervention in cooperatives is extremely great; between 1915 and 1970 there have been 946 different legislative actions dealing with cooperatives, and between 1984 and 1994 there were some 230 more (Patronis, 2002, pp. 25-26). 
civic ones. ${ }^{14}$ Profits were distributed only among the members working in the cooperative (Adam, 2012). These two aspects raised the popularity of social cooperatives between activists, who started to form assemblies, committees and networks for its promotion, emphasizing the solidarity aspect of this economic approach. Against the precarious conditions of the neoliberal market, the turbulent years that followed saw many collectives adopting and somehow appropriating the legal status of a social cooperative.

We found a window. The form of social cooperative has become property of the movement community. We know that whenever we hear about a social cooperative, we know that the people who work will be co-workers, they will be equal partners and they will make their decisions based on their general assemblies. (Int.2o)

The de-legitimation of SYRIZA due to its "backflip" in the summer of 2015 also raised skepticism towards social economy, since the party was among the main institutional actors advocating for it. The new bill on social economy in 2016 sparked an open debate between bureaucrats, government officials and the movements. Some collectives started referring only to solidarity and not social economy, others favoured the frame of cooperative economy and started to use the term "workers' collective", while others blended social economy with the approach of commons as something distant from the state and market (field notes Thessaloniki, 2016; field notes Athens, 2017). One way or the other, legislative attention to social cooperativism, public consultation between the state and movement actors and the expansion of self-managed collectives, brought to the forefront the forgotten scene of labour as a space for interaction between the state and movement actors.

\subsubsection{Aggressive and Defensive Self-management}

Drawing on the roots of self-management is helpful in understanding how cooperativism was diffused and legitimized within the social movement community; nevertheless, legitimation does not necessarily equal blind appreciation. The range of criticism is broad within the movement community: some argue that self-management is doomed to fail without the seizure of power by the proletariat; while others claim that the power of the capitalistic market is able to absorb and co-opt every individual

14 This welcoming policy changed some years later with social cooperatives being subject to the same taxation as every other business. 
effort. Harsher criticism points out that self-managed cooperatives tend to commercialize the movement culture, while milder voices are at best skeptical towards cooperatives. The latter occurred in the case of grassroots unions which, although expressing sympathy towards cooperatives, did not eventually accept them in their associations (Int.49). However, the opposite also took place, with some collectives hesitating to network and coordinate actions with others, due to the members' previous unpleasant experience in trade unionism (Int.30). The different preferences expressed by cooperatives and other fractions of the social movement community do not constitute random views; rather, they point to the activation of category formation mechanism under conflictual and complementary approaches.

Category formation stands for the creation of a social category, which 'consists of a set of sites that share a boundary distinguishing all of them from and relating all of them to at least one set of sites visibly excluded by the boundary' (McAdam et al., 2001, p. 142). The mechanism of category formation has been identified many times in the process of actor constitution, mostly with regards to ethnic rivalries (Alimi et al., 2015, Chapter 5; McAdam et al., 2001, pp. 143-144, 313-317). Rather emphatically, McAdam et al. have emphasized that 'category formation creates identities' (2001, p. 142). As we mentioned earlier, the characteristics of the cooperatives' category are rather blurred, since it seems to refer to different actors, with different values and differences in their organizational principles and resources. ${ }^{15}$ Nevertheless, this fluid category runs through all the factors transversely, but is mostly depicted in the factor of identity.

Regarding the organizational structure, we mentioned that emulation and coordinated action are intertwined with the category formation mechanism. Nevertheless, as Diani observes, 'it is the definition of a shared identity which qualifies a movement network vis-à-vis a coalition network, and draws its boundaries', with the 'circulation of meaning and mutual recognition' occupying a significant place (2003a, p. 10). Therefore, in our context, category formation refers to the gradual creation of a cooperative identity, blended with the principles of self-management. Despite some minor differences in their organizational models, the lack of a respective tradition, coupled with their diffusion and the development of links with traditional movement actors through their resources, assisted the mutual

15 The lack of tradition in social economy brought different actors, such as parties, interest groups, SMOs and squats to compete for its representation. During the fieldwork period, these actors gradually started to create their own boundaries and definitions of what they represent. 
identification of cooperatives as similar forms that promote equal labour relations. In this respect, the early stage of category formation mechanism does not follow solid, concrete and compact beliefs and practices. Instead, built on a post-modern approach, this fluid category is based on the aggregation of different elements that denounce market inequalities and precarious labour conditions. To capture how the category of self-managed cooperativism is being formed, we focus on the aggressive and defensive types of self-management.

Aggressive and defensive self-management have been used in the context of the Argentinean recuperated factories in the aftermath of the 2001 economic crisis. Defensive self-management was used to describe those cases of recuperated factories that defended self-management as a way of re-assuring the maintenance of workers' jobs under equal labour relations. Aggressive self-management, on the other hand, aimed to describe those cooperatives in which self-management was pictured as the necessary instrument for broader social transformation (Davranche and Hassoun, 2015, p. 67). We cannot deny that the aforementioned distinction has many subjective connotations. But it also serves to provide some signs about the different (and to some extent contradictory) approaches to self-management within the same category. Therefore, applying such a categorization is rough and maybe unfair, since it is difficult to take into consideration all the different aspects of cooperatives. With regards to the Greek case, we are aware that this can be problematic, since cooperatives are in their initial stages and still develop their identity. Nevertheless, by applying the concepts of aggressive and defensive self-management, we are in a better position to understand the plethora of features that make up the category of self-managed cooperativism.

The aggressive type of self-management is among the main reasons behind the establishment of collectives within social centres. At the same time though, aggressive self-management can be also found in cooperatives that operate as legal entities in the market. We demonstrated earlier that Germinal was the result of a careful plan, drawn by some members of the Libertatia squat in order to create a parallel system,

a political organization which would base its structures on that (selfmanagement); which would be economically self-sufficient and operate on a national level. [...] If there is no political aim and the members do not have political characteristics, then it would just create an islet within the system, and it will actually reproduce it. Only when self-management spreads will it be able to acquire revolutionary characteristics. (Int.25) 
The same also goes for Belleville, which tried, but failed, to develop other self-managed structures, such as a publishing house (Int.25). Similarly, Pagkaki's members clearly state that,

we didn't join forces only to find a solution for our livelihood in times of crisis, but because we are inspired by this logic: to explore and develop today the relationships of equality and solidarity we dream for a future society. [...] We consider our workers' collective part of the struggles for the social transformation into a society in which the laws of profit, the professional politicians and the power experts won't rule our lives' (Pagkaki, 2013).

Similarly, NoC declares that one of its aims is 'to coordinate our participation with the struggle for the broader social transformation [...] via our direct connection with the autonomous labour movement and the movement of social and solidarity economy' (NoC, 2012). In this context, the factory of Vio.Me occupies a prominent position. Apart from the occupation of the means of production, which depicts the realization of the radical left and libertarian imaginary, in 2014 Vio.Me introduced in its statute the concept of "solidarity supporter" by trying to socialize the factory's control. Through a monthly fee exchangeable with Vio.Me products, the solidarity supporter participates in the cooperative's open assemblies with a consulting vote. According to Vio.Me's official announcement, this aims to open 'to the majority of society, the opportunity to participate in the democratic processes of the operation of the factory. We ask you to become part of this struggle that opens the way for factories to pass into the hands of workers, for a society without bosses and exploitation' (VWA, 2014).

When it comes to defensive self-management, things become slightly blurred. Both Ekdosis ton Sinadelfon (Int.23) and Lacandona (Int.45; Int.46) argued that they are not political groups with concrete political direction, and that their participation in NoC and their self-managed orientation is their political characteristic. Similarly, Akivernites Polities does not define itself as a political group. It does, however, consider its action as part of the movement for social change. Nevertheless, one member noted that,

cooperatives are the rearguard; they are the efforts for survival and exemplification. They are not the places where the most significant battles will take place. The most important battles will be given by the workers, the employees, the migrants, the excluded, and the proletariat. [...] We miss the element of disobedience, of rupture against the laws and 
orders; and that's why cooperatives are constantly on a fluctuation. Either they will be coopted, or destroyed, or they will help only as an example of different social organization without bosses, in order to help the real actors to occupy the means of production and change the society. (Int.31)

From this point of view, cooperatives fit Diani's (2003b, p. 302) definition of non-conflictual movements. Nevertheless, their members (and sometimes as organizations) do participate collectively in protest events, while the interviewee's sharp criticism does not apply to the self-managed structures within social centres or the occupied factory of Vio.Me, which clearly urge their "constituents" to mobilize. Other cooperatives offer more complex explanations. For example, a member of Poeta argued that the cooperative does not have any political projection of self-management: 'We just want to live with dignity without having dependent labour relations. [...] We didn't come here to solve our political disagreements, but to work', to later add that, as is the case in other cooperatives, their effort 'is part of the broader struggle for the revolutionary social change; it's a nice way for people to train themselves to work and live without bosses' (Int.44).

While the odds of adopting a defensive strategy would normally be on the side of the cooperatives with less politicized members, many interviewees agreed that this is not the case. Speaking of that, an interviewee pointed out that there are three categories of cooperatives: those who chose this form only in order to open a relative low-cost enterprise with less taxation; those who promote self-management as a worldview and support networking, and

there are many cooperatives staffed by activists who clearly distinguish it (activism and labour). They participate in social centres, squats or parties but (in their view) cooperatives are only for making a living. For instance, the members of (name of the cooperative) are activists, but they chose not to participate in NoC, arguing that the cooperative is only a way to make money, make a living and not to promote their ideology. (Int.48)

The cooperatives' willingness to network seems to be a crucial aspect that distinguishes aggressive from defensive self-management. This derives both from the narrative expressed earlier, and from in-group and out-group brokerage as analysed in the section on resources. In these terms, networks are not only modes of coordination with intense or loose ties with regards to the allocation of resources, but they also picture a deeper understanding with regards to the definition of identity boundaries (Diani, 2015, p. 198). At the same time though, some cooperatives seem rather hesitant to situate 
themselves in one of these two extremes. They are also skeptical of how to relate and interact with social and solidarity economy networks. A member from Eklektik for example argues that, 'we made it clear from the beginning that here, we want to make a decent living' (Int.26), something that would have situated the cooperative in the defensive style of self-management. But, as the interviewee continued, Eklektik tries to create a network with other self-managed cooperatives and also to engage female and agricultural cooperatives, while any potential surpluses will be distributed for the support of other cooperatives. A clearer stance is adopted by Perisilogi, of which the members argue that no matter how networked a cooperative is, 'it is an enterprise with social sensitivities shared by all the members, but we don't want to make it political. We are a social cooperative enterprise, not a political space' (Int.22).

In terms of the social appropriation mechanism, self-managed cooperatives try to diffuse their form of organization to more conventional cooperatives, either by applying specific criteria and conditions, as we saw with in-group brokerage through resources, or by incorporating them into their networks via their organizational structure. In times of economic hardship, the cooperatives' success seems as the most important factor in becoming an example to be imitated. Nevertheless, the promotion of a political stance through the work environment is not only a matter of collective desire, but also an issue of time and fatigue. As many interviewees have stressed, working in cooperatives includes many personal compromises; they have often contributed unpaid labour that would otherwise be probably translated to protest claims against the employers. Additionally, thinking in double gears, meaning both as members who want their enterprise to succeed and as political subjects who seek equality inside the competitive market environment, creates stress and confusion to the members; while leaving aside personal disagreements for the sake of the collective is not an easy task, especially for people without similar experience in participatory collective management (Int.25; Int.44). As it was stressed by all the interviewees, challenging these internal dynamics has great impact on both the collective and the individual identity. Moreover, participation in the cooperatives' weekly assemblies as well as red shifts and other actions included in the out-group brokerage mechanism, are considered part of the job and in many ways, decrease the members' willingness to involve themselves in purely political actions (Int.30; Int.48).

The aforementioned narratives witness some clear cases of aggressive self-management, but they also show the different dynamics that gradually advocate for the construction of category formation mechanism. However, 
the cooperatives' identity does not only concern self-management. Among others, the anti-fascist element seems to be strongly embedded in the social movement scene of labour. The long list of actions includes the public screening of anti-racist documentaries (Int.30), the organization of common events with migrants, such as the reading of fairy tales in Greek and Arabic for Greek and migrant kids (Int.31); the establishment of vegetable gardens within refugee camps (Int.22), or the creation of self-managed structures within social centres to be run only by refugees (field notes, Thessaloniki, 2016). Moreover, most of the interviewees argued that when customers raise discriminatory claims or are identified as Golden Dawn supporters, they are immediately expelled.

Lastly, with regards to the cooperatives' identity, we cannot leave aside their spatial dimension, where respect to the workers is also translated as respect to the community. Unlike many profit-driven enterprises, cooperatives show total compliance with the laws against territorial trespassing and the requirements for people with disabilities (Pagkaki, 2015), host and participate in grassroots neighbourhood initiatives (Int.30), and adjust their operation to quiet hours' regulations; these are some characteristics that, in some cases, drive them to conflict with profit-driven enterprises (Int.45; Int.47). Through the lens of a spatial approach, cooperatives also seem to blend their civic characteristics with the activist ones. Apart from their internal organizational structure, the organization of political and social events and their anti-fascist character provide these entities with a movement-friendly label. As an interviewee claimed, here there are two enterprises operating under self-management, something that also gives the neighbourhood a special character. It is not that easy for someone wearing a Golden Dawn T-shirt to walk around' (Int.20), while other cooperatives have raised similar claims as well. As such, the category formation mechanism contributes to the expansion of identity boundaries also in the physical space, signaling a safe place (and in some cases a safe district) from the movements' potential opponents.

\subsection{Conclusion}

This chapter unravels the central mechanisms and sub-mechanisms that activate the process of boundary enlargement with regards to the social movement scene of labour (Table 5.2).

During the effort to produce equal labour relationships for their members, self-managed cooperatives in Greece focused a great deal of attention on 
Table 5.2 Mechanisms and sub-mechanisms in the social movement scene of Labour

\begin{tabular}{lll}
\hline & Mechanisms & Sub-mechanisms \\
\hline Organizational Structure & Emulation & \\
& Coordinated Action & \\
\hline Resources & In-group Brokerage & \\
& Out-group Brokerage & Emulation \\
\hline Identity & Social Appropriation & \\
& Legitimation & \\
& Diffusion & \\
& Certification & \\
& Category Formation & \\
\hline
\end{tabular}

their organizational structure. Internal organization does not only result in the better operation of the respective enterprises; it also serves as a means of diminishing any potential rise of hierarchy and promoting equality in the workplace. To this extent, the pluralism observed with regards to the cooperatives' decision-making systems and internal designs, seems rather innovative when compared to the administrational formats found in typical businesses. Nevertheless, a closer look reveals that this was not a product of coincidence. Rather, it was mainly achieved through an emulation mechanism, allowing cooperatives to transfer the respective organizational designs of SMOs within the labour market. Of course, the reproduction of SMOs' settings in the labour market varied, with some cooperatives being more structured or well organized than others. However, all of them share a great degree of cohesion when it comes to the application of direct-democratic proceedings. Emulation, however, should not be interpreted as a panacea for the elimination of inequalities in the workplace. Similar to activists' recruitment, cooperatives can be found to pay too much attention to the personal relations and political values of potential members. Although this marks their unique approach to labour, it became rather problematic as it did not define the entry and exit procedures in cases when internal fights proved to be unsolvable.

The mechanism of emulation brought to light another mechanism often found in social movement studies, namely coordinated action. This mechanism finds its roots in the early steps of self-organized collectives and self-managed cooperatives. Sharing of practical information and exchange of positive and negative experiences brought cooperatives quite close to each other and favoured their diffusion. Individual efforts to form connections between the cooperatives occurred with the collective organization of events, workshops and festivals about self-management, enabling the 
gradual rise of cooperatives. Apart from helping the diffusion of cooperatives, the coordination between them played a vital role in the production of a common framework and contributed to the creation of networks able to offer practical assistance when needed. Both emulation and coordinated action were important mechanisms, which contributed towards the enlargement of the organizational boundaries of the social movement scene of labour. What comes next is the factor of resources.

Being among the basic actors of the social movement scene of labour, self-managed cooperatives struggle for workplace equality. In order to do so, cooperatives urge for horizontal decision-making systems and participatory management. However, our explanation for how the boundaries have been enlarged in the social movement scene of labour would be incomplete without considering the economic side of the cooperatives. Here, the factor of resources acquires particular interest, as it provides evidence of how economic entities interact with the voluntary environment of the social movement community, as well as how the social movement approaches communicate within the market environment. Focusing on the cooperatives' initial capital, we show how the political element merges with the need for employment, as well as some potential disadvantages that it might create. However, this interaction becomes more evident when it comes to the issues of pricing and socialization.

Acting against a profit-driven logic, cooperatives apply a social approach to valuing their services and products. In this respect, the in-group brokerage mechanism illustrates how the organizational networking is also expressed through resources, facilitating the organic connection among cooperatives. At the same time though, in the context of austerity, where the cooperatives' political and social character is sometimes at odds with economic success, this mechanism brings forward important dilemmas. Self-management directs the way something is produced, but what is equally important, both in terms of resources and identity, is to engage the society in a dialogue on what is produced (Katsoridas, 2016, p. 10). VioMe's solidarity supporter or the organization of consumer cooperatives follow this line, that is being able to direct the cooperatives' production towards the service of social needs and not the creation of fake ones. The simultaneous establishment of producers and consumers' cooperatives is also important in the long run. In particular, it sets the base for the creation of a small cooperative ecosystem that will prohibit potential market cooptation and will also help to find solutions with regards to the cooperatives' economic success equation.

Our attention to socialization also reveals how resources are used as a means of connecting self-managed cooperatives with traditional SMOs 
and other social movement actors. The emulation sub-mechanism studied in cooperatives' organizational structure was also present in resources, constituting a key component of the out-group brokerage mechanism. From the provision of the cooperatives' infrastructure hosting political and social groups, to the red shifts, out-group brokerage reveals how cooperatives not only manage to financially contribute to traditional SMOs, something particularly valuable in times of austerity; but how they also expand the sources of the social movement community.

Attention to identity reveals the cultural formation of the social movement scene of labour. To this extent, our analysis was divided in two chronological sections, in order to better capture its conception and evolution. Although not contentious in the strict sense of the term, the origins of the cooperative trend find their roots in the incorporation of self-organized practices into everyday life. Theoretical aspirations and practical limitations contributed to the appropriation of self-management, in a context lacking a respective culture. The gradual evolution of the first self-managed examples coincided with the onset of the crisis, triggering the mechanism of legitimation. Additionally, the introduction of a friendly legislative framework generated the mechanisms of certification and diffusion. The combination and sequence of these four mechanisms helped to demonstrate how the cultural background of cooperatives has been developed.

However, this development came to be confronted with criticism from many parts of the social movement community. On this ground, diversification gave space to gradual initiation of a category formation mechanism, through different and sometimes conflicting approaches. Our analysis tried to demonstrate how the formation of the cooperative identity, although in its first steps, has been built around the ideals of self-management. Although the vulnerabilities of the aggressive-defensive style of self-management made us cautious, this dichotomy serves to demonstrate that many cooperatives might be situated in the medium space, knitting the dynamic character of their identity. However, collective desire for self-management is only one of the factors that form the political element of cooperatives, as their dynamic identity is also influenced by everyday parameters, such as lack of time and fatigue. At the same time though, by incorporating the cooperatives' anti-fascist characteristics as well as their spatial approach, we aimed to complement the picture of the cooperatives' category formation and to expose that the enlargement of boundaries concerns a multiplicity of topics. 


\section{Bibliography}

Adam, S. (2012). Social Economy, Work Integration and Social Exclusion: The

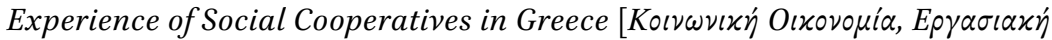

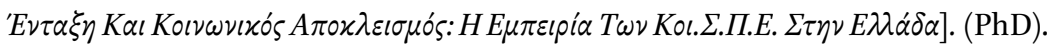
Democritus University of Thrace, Retrieved from: https://phdtheses.ekt.gr/eadd/ handle/10442/29850 Last Accessed: 28 April 2020

Alimi, E. Y., Bosi, L., \& Demetriou, C. (2015). The Dynamics of Radicalization: A Relational and Comparative Perspective. New York: Oxford University Press.

Bourantas, D., \& Papadakis, V. (1996). Greek Management: Diagnosis and Prognosis. International Studies of Management \& Organization, 26(3), 13-30.

Davranche, G., \& Hassoun, M. (2015). Argentina: The Lesson of Argentinazo (T. Dritsas \& C. Spatharakis, Trans.). In G. Davranche (Ed.), Self-Management: An Idea Always up to Date. Athens: Ekdosis ton Sinadelfon

Diani, M. (2003a). Introduction: Social Movements, Contentious Actions, and Social Networks. In M. Diani \& D. McAdam (Eds.), Social Movements and Networks: Relational Approaches to Collective Action (pp. 1-18). Oxford New York: Oxford. Diani, M. (2003b). Networks and Social Movements: A Research Programme. In M. Diani \& D. McAdam (Eds.), Social Movements and Networks: Relational Approaches to Collective Action (pp. 299-319). Oxford New York: Oxford.

Diani, M. (2013). Organizational Fields and Social Movement Dynamics. In The Future of Social Movement Research. Minneapolis: University of Minnesota Press. Diani, M. (2015). The Cement of Civil Society. Cambridge: Cambridge University Press. Diani, M., \& Mische, A. (2015). Network Approaches and Social Movements. In D. Dela Porta \& M. Diani (Eds.), The Oxford Handbook of Social Movements (pp. 306-325). New York: Oxford.

Freeman, J. (1972). The Tyranny of Structurelessness. Berkeley Journal of Sociology, 2(1), 151-164.

Gall, G. (2010). Resisting Recession and Redundancy: Contemporary Worker Occupations in Britain. WorkingUSA, 13(1), 107-132.

Grasseni, C. (2014a). Food Activism in Italy as an Anthropology of Direct Democracy. Anthropological Journal of European Cultures, 23(1), 77-98.

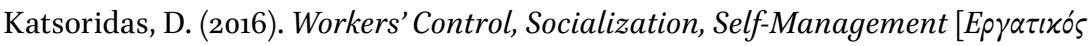

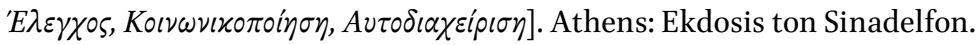

Kioupkiolis, A., \& Karyotis, T. (2015). Self-Managing the Commons in Contemporary Greece. In D. Azzellini (Ed.), An Alternative Labour History: Worker Control and Workplace Democracy (pp. 298-328). London: Zed Books.

Kokkinidis, G. (2012). In Search of Workplace Democracy. International Journal of Sociology and Social Policy, 32(3), 233-256. 
Kokkinidis, G. (2015). Spaces of Possibilities: Workers' Self-Management in Greece. Organization, 22(6), 847-871. doi:10.1177/1350508414521098

Kritsantonis, N. (1998). Greece: The Maturing of the System. In R. Hyman \& A. Ferner (Eds.), Changing Industrial Relations in Europe (pp. 504-528). Oxford: Blackwell Malamidis, H. (2018). The Passage from Hierarchy to Horizontality: The SelfManaged Factory of Vio. Me, Greece. Zeitschrift für Kultur-und Kollektivwissenschaft, 4(1), 23-52.

Marcovitz, Y., Davis, A., \& Van Dick, R. (2007). Organizational Commitment Profiles and Job Satisfaction among Greek Private and Public Sector Employees. International Journal of Cross-Cultural Management, 7, 77-99.

McAdam, D. (2003). Beyond Structural Analysis: Toward a More Dynamic Understanding of Social Movement. In M. Diani \& D. McAdam (Eds.), Social Movements and Networks: Relational Approaches to Collective Action (pp. 281-298). New York: Oxford University Press.

McAdam, D., Tarrow, S. G., \& Tilly, C. (2001). Dynamics of Contention. Cambridge, U.K.; New York: Cambridge University Press.

Patronis, V. (2002). Between State and Market Forces: Greek Agricultural Cooperative Organizations in Transition Period. Paper presented at the 13 th Congress of the International Economic History Association Buenos Aires Last

Psychogios, A. G., \& Wood, G. (2010). Human Resource Management in Greece in Comparative Perspective: Alternative Institutionalist Perspectives and Empirical Realities. The International Journal of Human Resource Management, 21(14), 2614-2630.

Staggenborg, S. (2011). Social Movements (Rev. ed.). New York: Oxford University Press. Tilly, C., \& Tarrow, S. G. (2007). Contentious Politics. Boulder, Colo.: Paradigm Publishers.

Tilly, C., \& Tarrow, S. G. (2015). Contentious Politics (Second revised edition. ed.). New York, NY: Oxford University Press.

Varkaolis, O. (2012). Creative Resistances and Counterpower. Endeavors and Reflec-

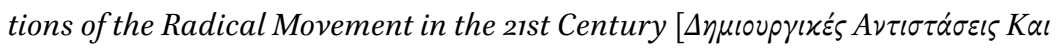

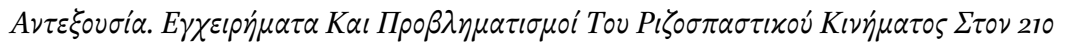
$A \iota \dot{v} \alpha$ ]. Athens: Kafeneion to Pagkaki Publications.

Williams, R. C. (2016). The Cooperative Movement: Globalization from Below. New York: Routledge.

\section{SMO Material}

Germinal. (2012). 'Notebooks on Self-management'. Retrieved from http://libertatiasquat.blogspot.gr/2012/10/blog-post_19.html (in Greek), Last Accessed: 28 April 2020 
Festival on Self-management: Presentation of Notebooks on Self-managementFestival on Self-management 8, 9, 10 June (2012, June 8). Kinimatorama. Retrieved from https://www.kinimatorama.net/event/20125 (in Greek), Last Accessed: 28 April 2020

NoC. (2012). 'Network of Cooperatives in Athens. Solidarity, Self-management, Collective'. (in Greek), Last Accessed: 28 April 2020

Pagkaki. (2013). 'Exploring the paths: Third year of the workers' collective Pagkaki' (in Greek), Last Accessed: 28 April 2020

Pagkaki. (2015, July). 'Five years Pagkaki. Every answer and a step, every step and a question.... Thoughts, Aims, Actions, Accounts'. Retrieved from http://pagkaki. org/5years (in Greek), Last Accessed: 28 April 2020

Trespass. (2016, July 19). 'Call for participation in the Second Euromediterranean “Workers' Economy” Meeting. Retrieved from https://www.trespass. network/?p=213\&lang=en, Last Accessed: 28 April 2020

VWA. (2014). 'Together we can make the gear turn - Sign up as a solidarity supporter of Vio.Me'. Retrieved from http://www.viome.org/2014/o2/together-we-canmake-gear-turn-sign-up.html, Last Accessed: 28 April 2020

\section{List of Interviewees}

Interviewee 19 - Male, 36-40 years old, Founding Member of the Cooperative Priza, Athens (28.9.16) - Email interview - Transcribed in Greek

Interviewee 20 - Female, 26-30 years old, Member of the Cooperative Belle Ville Sin Patron, Thessaloniki (23.5.16) - Audio recorded - Transcribed in Greek

Interviewee 21 - Male, 26-30 years old, Founding Member of the Cooperative Domino, Thessaloniki (3.7.16) - Audio recorded - Transcribed in Greek

Interviewee 22 - Male, 41-45 years old, Founding Member of the Cooperative Perisilogi, Thessaloniki (4.7.16) - Audio recorded - Transcribed in Greek

Interviewee 23 - Male, 56-6o years old, Founding Member of the Cooperative Ekdosis ton Sinadelfon, Athens (11.11.16) - Handwritten notes - Transcribed in Greek

Interviewee 24 - Female, 41-45 years old, Founding Member of the Cooperative Allos Tropos, Thessaloniki (29.6.16) - Audio recorded - Transcribed in Greek

Interviewee 25 - Male, 31-35 years old, Member of the Cooperative Belleville Sin Patron and founding member of Germinal, Thessaloniki (24.6.16) - Audio recorded - Transcribed in Greek

Interviewee 26 - Male, 36-40 years old, Founding Member of the Cooperative Eklektik and member of Spame, Thessaloniki (2.11.16) - Audio recorded - Transcribed in Greek 
Interviewee 28 - Male, 26-30 years old, Founding Member of the Cooperative Sociality, Athens (9.12.16) - Audio recorded - Transcribed in Greek Interviewee 30 - Female, 36-40 years old, Founding Member of the Cooperative Oreo Depo, Thessaloniki (2.7.16) - Audio recorded - Transcribed in Greek Interviewee 31 - Male, 36-40 years old, Founding Member of the Cooperative Akivernites Polities, Thessaloniki (23.5.16) - Audio recorded - Transcribed in Greek

Interviewee 34- Male, 31-35 years old, Member of Mikropolis Social Centre, Thessaloniki (27.7.16) - Audio recorded - Transcribed in Greek

Interviewee 44- Male, 41-45 years old, Founding Member of the Cooperative Poeta, Thessaloniki (13.10.16) - Audio recorded - Transcribed in Greek

Interviewee 45 - Female, 36-40 years old, Founding Member of the Cooperative Lacandona, Athens (26.9.16) - Audio recorded - Transcribed in Greek Interviewee 46 - Female, 36-40 years old, Founding Member of the Cooperative Lacandona, Athens (26.9.16) - Audio recorded - Transcribed in Greek Interviewee 47 - Female, 36-40 years old, Founding Member of the Cooperative Lacandona, Athens (26.9.16) - Audio recorded - Transcribed in Greek Interviewee 48 - Male, 31-35 years old, Member of the Cooperative Youkali, Athens (27.9.16) - Audio recorded - Transcribed in Greek

Interviewee 49 - Female, 31-35 years old, Founding Member of the Cooperative Pagkaki and Sporos collective, Athens (9.12.16 and 31.10.17) - Audio recorded - Transcribed in Greek

Interviewee 50 - Female, 41-45 years old, Founding Member of the Cooperative Pagkaki and Sporos collective, Athens (9.12.16 and 31.10.17) - Audio recorded - Transcribed in Greek

Interviewee $5^{1}$ - Male, 26-3o years old, Member of Sholio Squat, Thessaloniki (27.10.16) - Audio recorded - Transcribed in Greek 